\title{
Delayed pulmonary oedema following suicidal hanging
}

\author{
S Ahmad ${ }^{*}$, S Kamal', K Jamal \\ Senior Resident ${ }^{1 *}$, Department of Anaesthesiology and Critical Care, J N Medical College, Aligarh \\ Muslim University, Aligarh, Uttar Pradesh, India. Senior Resident ${ }^{2}$, Department of Anaesthesia, \\ Paras Global Hospital Darbhanga, Bihar, India.
}

Corresponding author: kamalshadab@gmail.com

\begin{abstract}
Suicidal hanging usually leads to death within a few minutes. The patient, if rescued, may develop respiratory distress, pulmonary oedema, convulsions, raised intra cranial pressure and unconsciousness immediately after the incident. We report a case of suicidal hanging in a young female, brought to hospital in a conscious state with restlessness and anxiety. She developed pulmonary oedema after twelve hours, and was resuscitated successfully.
\end{abstract}

Keywords: Suicidal hanging; hypoxia; pulmonary oedema; acute respiratory distress syndrome; raised intra cranial pressure

\section{Introduction}

The majority of victims of suicidal hanging are young and survivors are uncommon. Death usually occurs within few minutes of hanging. In survivors, respiratory and neurological complications develop immediately in most patients. Pulmonary complications are the cause of mortality in most hospital deaths. Pulmonary oedema, one of the most common complications occur in patients immediately following their rescue from acute airway obstruction or suicidal hanging. ${ }^{1}$

We present a case of suicidal hanging in which pulmonary oedema developed 12 hours after the incident. She presented in a conscious state with restlessness and features of cerebral anoxia and later developed non cardiogenic pulmonary oedema. Early resuscitation and aggressive management led to complete recovery without any residual neurological deficit.

\section{Case report}

An 18 year old female was brought to the casualty department of our hospital with an alleged history of suicidal hanging by her cloth shawl (dupatta). The patient was rescued by her parents within a few minutes and brought to hospital within 20 minutes. On examination she was conscious, her pulse rate was $124 / \mathrm{min}$ and blood pressure was $110 / 60 \mathrm{mmHg}$. Pupils bilaterally reacted normally to light. On auscultation chest was bilaterally clear with adequate air entry, but patient was tachypnoeic with a respiratory rate of $30 / \mathrm{min}$. Upper airway reflexes were present. Pulse-oximetry revealed $\mathrm{SpO}_{2} 90 \%$ and arterial blood gas (ABG) analysis showed $\mathrm{PaO}_{2} 80 \mathrm{mmHg}, \mathrm{PaCO}_{2} 29 \mathrm{mmHg}, \mathrm{pH}$ 7.26, base excess (BE) $9.2 \mathrm{mEq} / \mathrm{L}$ and $\mathrm{SpO} 2$ $90 \%$ on Hudson mask with oxygen flow rate of $6 \mathrm{~L} / \mathrm{min}$. Chest X-ray and CT scan head were normal and X-rays of cervical spine (AP and lateral view) revealed no bony injury. Conservative management done in ICU included propping up the patient and providing oxygen with Hudson mask with reservoir bag. After $12 \mathrm{hrs}$ patient developed respiratory distress with coughing frequently and gradually her $\mathrm{SpO}_{2}$ dropped to $74 \%$. On auscultation bilateral crepitations were present in chest, Glasgow Coma Scale was E1V2M5, blood pressure was $82 / 54 \mathrm{mmHg}$ and pulse rate was $132 / \mathrm{min}$. Chest $\mathrm{X}$-ray showed bilateral diffuse infiltrates consistent with pulmonary oedema.

Immediately, her trachea was intubated orally with $7.0 \mathrm{~mm}$ ID cuffed endotracheal tube after intravenous ketamine $100 \mathrm{mg}$ and succinylcholine $75 \mathrm{mg}$. Patient was attached to a ventilator with pressure controlled ventilation mode with respiratory rate of $12 / \mathrm{min}$, inspiratory pressure $14 \mathrm{~cm}$ of $\mathrm{H}_{2} \mathrm{O}$, PEEP $8 \mathrm{~cm}$ of $\mathrm{H}_{2} \mathrm{O}$ and $\mathrm{FiO}_{2}$ of 1.0 after administration of vecuronium bromide $4 \mathrm{mg}$ and dexamethasone $8 \mathrm{mg}$ intravenously. The vital parameters post ventilation were pulse rate of $120 / \mathrm{min}$, blood pressure 124/80mmHg, $\mathrm{SpO}_{2} 94 \%$ on $\mathrm{FiO}_{2}$ of 1 . Prophylactic antibiotics were administered.

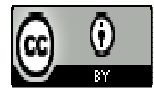

(C) 2017. Ahmad et al. This is an Open Access article distributed under the terms of the Creative Commons Attribution License (http: //creativecommons.org/licenses/by/4. 0), which permits unrestricted use, distribution, and reproduction in any medium, provided the original work is properly credited 
After one hour of therapy, $\mathrm{SpO}_{2}$ further dropped to $70 \%$ and patient developed frank pulmonary oedema with extensive fine crepitations all over the chest and pink frothy secretions appeared in the breathing system. Controlled ventilation was continued with PEEP of $10 \mathrm{cmH}_{2} \mathrm{O}$. She was given furosemide $40 \mathrm{mg}$ intravenously, repeated 8 hourly. After 2 hours patient's ABG revealed $\mathrm{PaO}_{2} 90 \mathrm{mmHg}, \mathrm{PaCO}_{2} 32 \mathrm{mmHg}, \mathrm{SpO}_{2} 96 \%$ on $\mathrm{FiO}_{2}$ at 1 . Her chest condition markedly improved after $14 \mathrm{hrs}$ of ventilation. $\mathrm{ABG}$ analysis showed $\mathrm{PaO}_{2} \quad 110 \mathrm{mmHg}, \quad \mathrm{PaCO}_{2}$ $38 \mathrm{mmHg}$, pH 7.45, $\mathrm{SpO}_{2} 98 \%$ on $\mathrm{FiO}_{2}$ at 0.5 . She regained consciousness, and was put on synchronized intermittent mandatory ventilation (SIMV) mode with $\mathrm{FiO}_{2}$ at 0.4 for the next 12 hrs. After 24 hours (2nd day) she was fully conscious. Her $\mathrm{SpO} 2$ was $99 \%$ on $\mathrm{FiO}_{2}$ at 0.4 . Chest X-ray AP view was normal. ABG analysis revealed $\mathrm{PaO}_{2} 112 \mathrm{mmHg}, \mathrm{PaCO}_{2} 40 \mathrm{mmHg}, \mathrm{pH}$ 7.40 and $\mathrm{SpO}_{2} 99 \%$ on $\mathrm{FiO}_{2}$ of 0.4. As her condition had improved, she was extubated. Post extubation her $\mathrm{SpO}_{2}$ was $97 \%$ on $\mathrm{FiO}_{2}$ of 0.4 by facemask. Chest radiograph demonstrated clear lung fields. Nebulisation and chest physiotherapy was continued. Thereafter she made an unremarkable recovery with no apparent residual lung or brain damage.

\section{Discussion}

The incidence of hanging in India is approximately $25 \%$ of total cases of suicide. ${ }^{2}$ Pulmonary complications like pulmonary oedema, bronchopneumonia, acute respiratory distress syndrome (ARDS) and cerebral oedema have been reported in most hospital deaths. ${ }^{3}$ The pulmonary oedema may be of neurogenic origin or secondary to negative intra-thoracic pressures generated as victim attempts inspiration through an obstructed airway. Negative pressure pulmonary oedema (NPPE) has been described to be a cause of ARDS and failure to consider NPPE in the differential diagnosis of ARDS may lead to unnecessary and potential lethal complications. While early recognition may herald NPPE or post obstructive pulmonary oedema (POPE), an obvious underlying cause may be absent after emergence from unintentional upper airway obstruction. ${ }^{4}$ Neurogenic pulmonary oedema results from a centrally mediated, massive, sympathetic discharge which produces intense, generalized, but transient vasoconstriction with a resultant shift of blood from systemic to pulmonary system. ${ }^{5}$ The pulmonary vasoconstriction also increases permeability by disrupting the permeability barrier.

The incidence of pulmonary oedema associated with airway obstruction has been estimated as $11 \%$ in adults requiring active airway intervention for acute airway obstruction of varying aetiology. ${ }^{6}$ The hypoxia induced hyper adrenergic state causes translocation of blood from systemic to pulmonary circulation and an increase in both pulmonary vascular resistance and pulmonary capillary permeability. ${ }^{7}$

The strategy of management should target to get adequate oxygenation and cerebral perfusion. ${ }^{1}$ In the presence of respiratory distress (hypoxia) with or without pulmonary oedema tracheal intubation and mechanical ventilation are indicated. PEEP (positive end expiratory pressure) has its definite role in the treatment of pulmonary oedema, but at the same time it also lead to increased intracranial pressure, so one has to weigh its use according to the patient's condition. ${ }^{8}$

Re-establishment of a patent airway may not provide the proper oxygenation even with a clear chest as occurred in our patient. Such patients may require aggressive oxygen therapy for adequate oxygenation. Pulmonary oedema is reversible in most of the cases once recognized and treated.

To conclude, patients rescued from suicidal hanging or strangulation even with a clear chest must be treated with aggressive oxygen therapy and monitored closely in ICU as they may develop pulmonary oedema even after 12 hours following the event.

\section{References}

1. Oswalt CE, Gates GA, Holmstrom MG. Pulmonary oedema as a complication of acute airway obstruction. JAMA 1977;238:1833-35. http://dx.doi.org/10.1001/jama.1977.03280180037 022

PMid:333133

2. Trivedi JK, Rohitkant S, Rajul T. Suicide: An Indian Perspective. JIMA 2005; 103: 78-84.

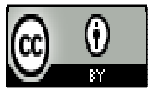

(C) 2017. Ahmad et al. This is an Open Access article distributed under the terms of the Creative Commons Attribution License (http: //creativecommons.org/licenses/by/4. 0), which permits unrestricted use, distribution, and reproduction in any medium, provided the original work is properly credited 
3. Kaki A, Crosby ET, Lui ACP. Airway and Respiratory management following non-lethal hanging. Can J Anaesth 1997; 44:445-50. http://dx.doi.org/10.1007/BF03014468 PMid:9104530

4. Ackland GL, Mythen MG. Negative pressure pulmonary oedema as an unsuspected imitator of acute lung injury/ARDS. Chest 2005; 127: 18678 . http://dx.doi.org/10.1378/chest.127.5.1867-a PMid: 15888877

5. Theodore J, Robin ED. Pathogenesis of neurogenic pulmonary oedema. Lancet 1975; 2: 745-51. http://dx.doi.org/10.1016/s0140-6736(75)90729-1

6. Fishman CM, Goldstein MS, Gardener LB. Suicidal Hanging, An association with Adult Respiratory Distress Syndrome. Chest 1977; 71: 225-7.

7. Lang SA, Duncan PG, Shephard DAE, Ha HC. Pulmonary oedema associated with airway obstruction. Can J Anaesth 1990; 37: 210-8. http://dx.doi.org/10.1007/BF03005472 PMid:2178789

8. Aidnis SJ, Lafferty J, Shapiro HM. Intra-cranial responses to PEEP. Anesthesiology 1976; 45: 275-86.

http://dx.doi.org/10.1097/00000542-19760900000004 